\title{
An adsorption-catalysis pathway towards sustainable application of mesoporous carbon nanospheres for efficient environmental remediation
}

Muhammad Rizwan Azhar ${ }^{a}$, Yasir Arafat ${ }^{b}$, Yijun Zhongb, Mehdi Khiadania, Moses O. Tade $^{b}$, Shaobin Wang ${ }^{b, c}$, Zongping Shao*b

a School of Engineering, Edith Cowan University, 270 Joondalup drive, WA, 6027, Australia.

b WASM, Curtin University, GPO Box U1987, Perth, WA, 6845, Australia.

c School of Chemical Engineering, The University of Adelaide, SA 5005, Australia

*Correspondence author: email: zongping.shao@curtin.edu.au

Supplementary information

This file contains supplementary information related to main text; all the figures (S1-S9) are discussed in the main paper. 


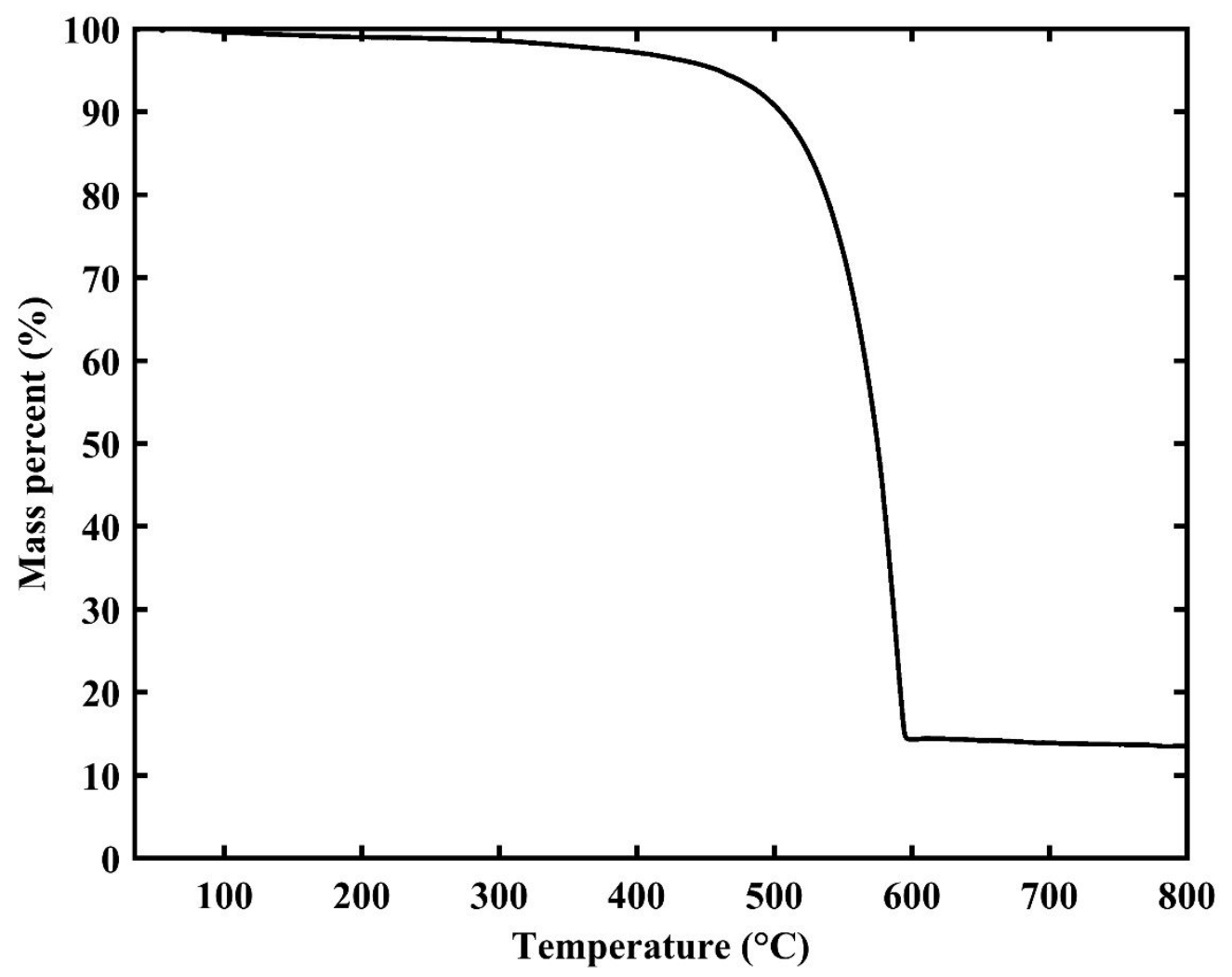

Figure S1. Thermal stability study of carbon nanospheres through TGA

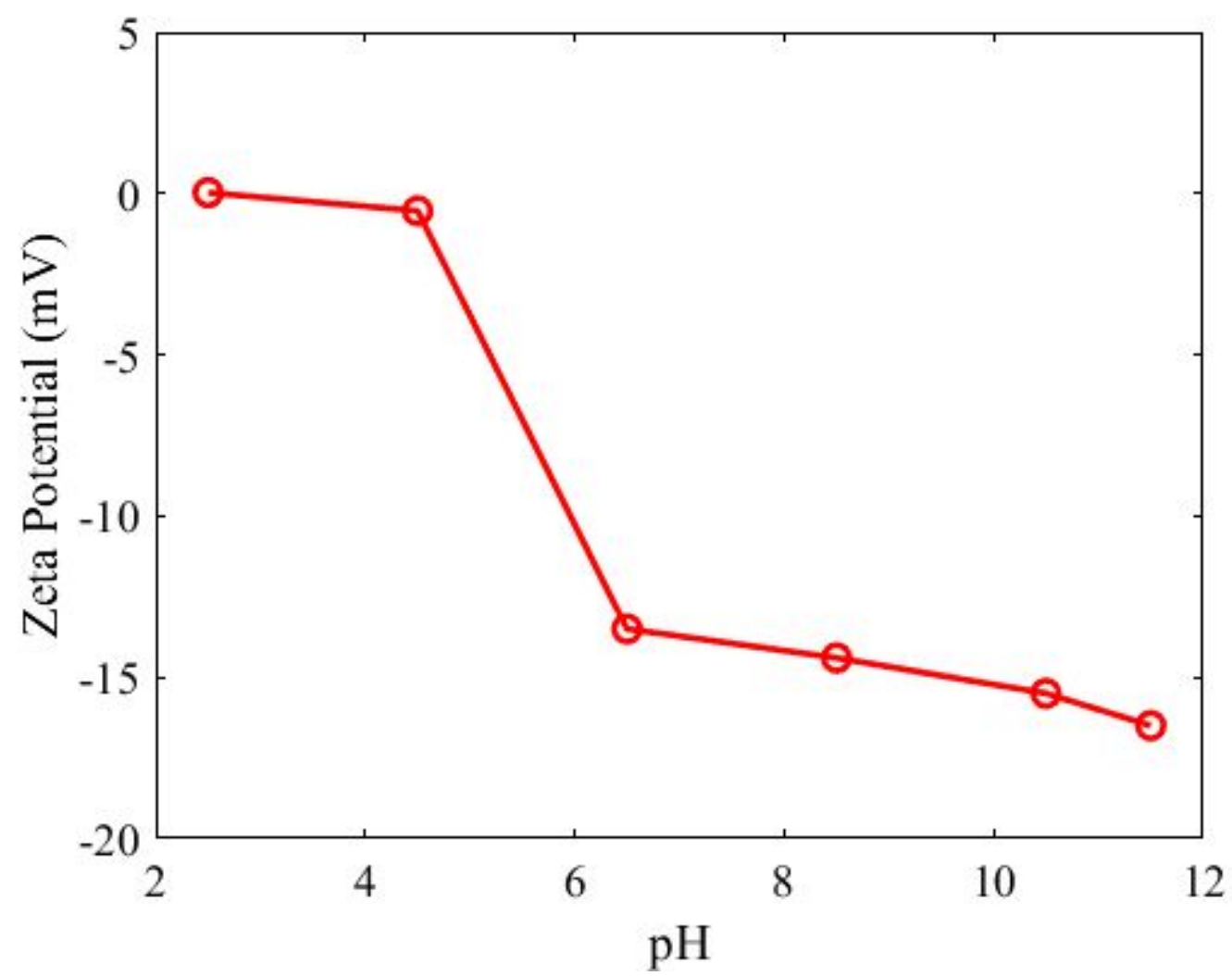

Figure S2. Effect of $\mathrm{pH}$ on zeta potential for MCNS 


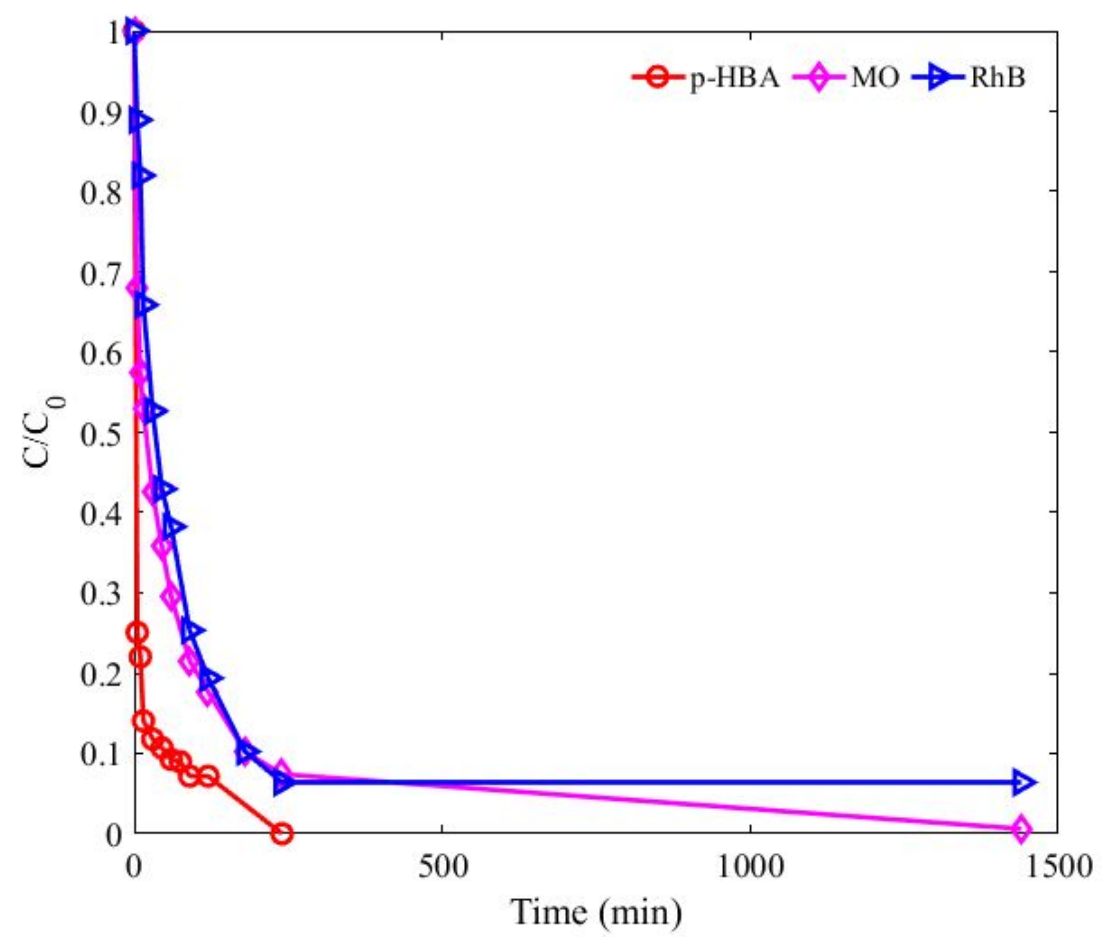

Figure S3. Adsorption kinetics of p-HBA, MO and RhB on MCNS 


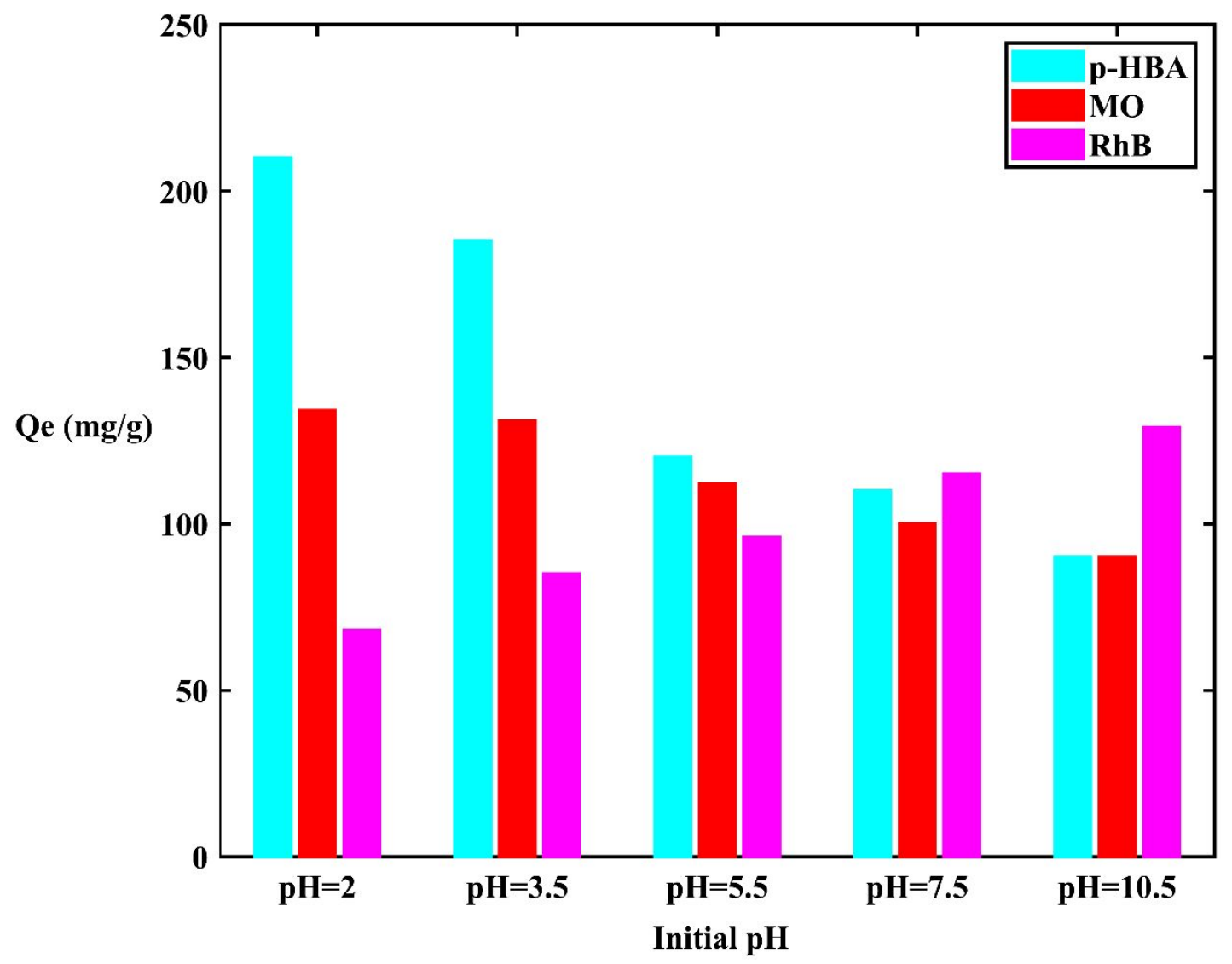

Figure S4. Effect of initial $\mathrm{pH}$ on adsorption of organic contaminates on MCNS 


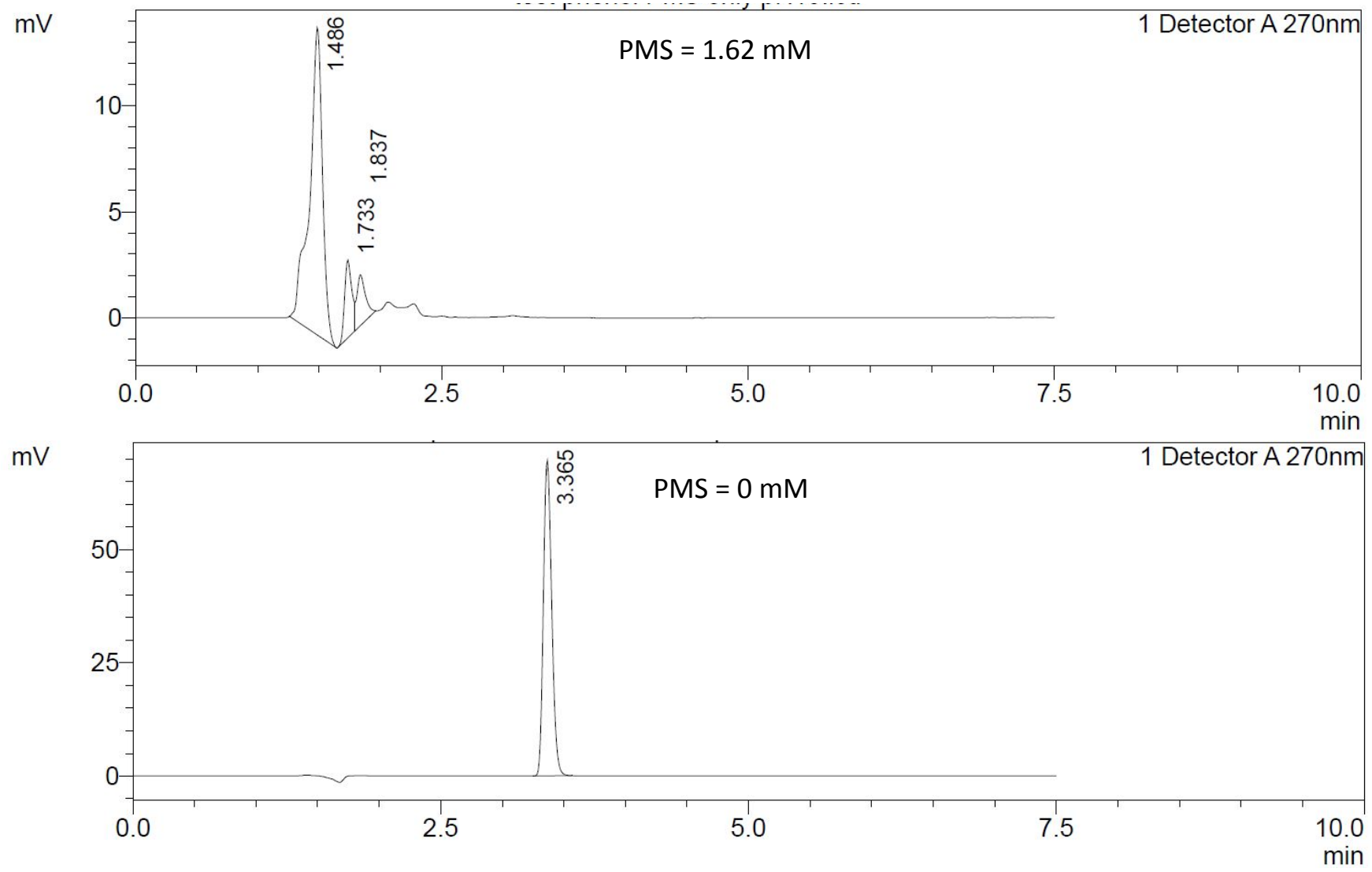

Figure S5. Peak shift of phenol at $\mathrm{pH}=11.5$ in the presence/absence of PMS without any catalyst 

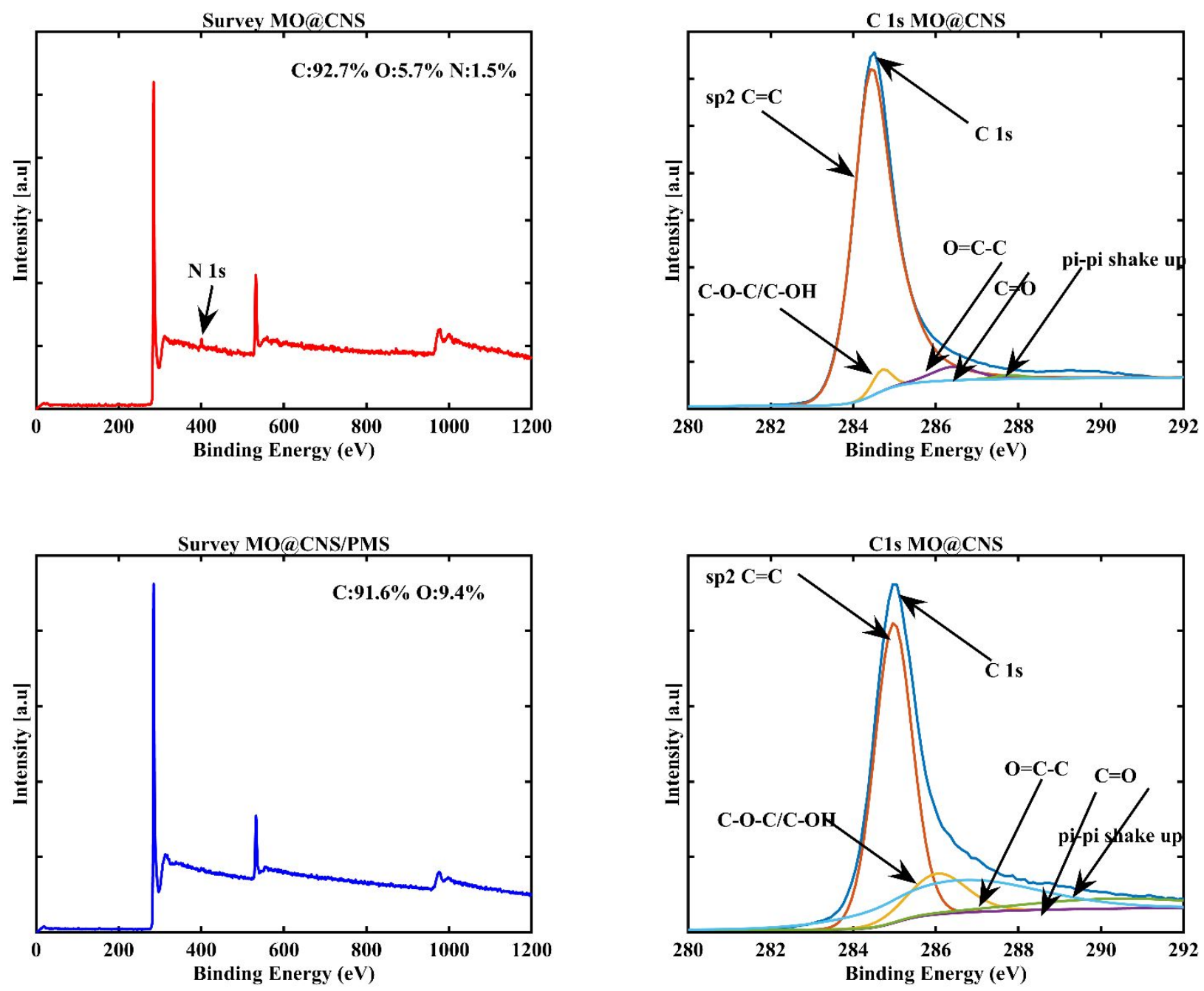

Figure S6. Survey and high-resolution C 1s XPS spectra of MO adsorbed MCNS and after using in phenol degradation with PMS 

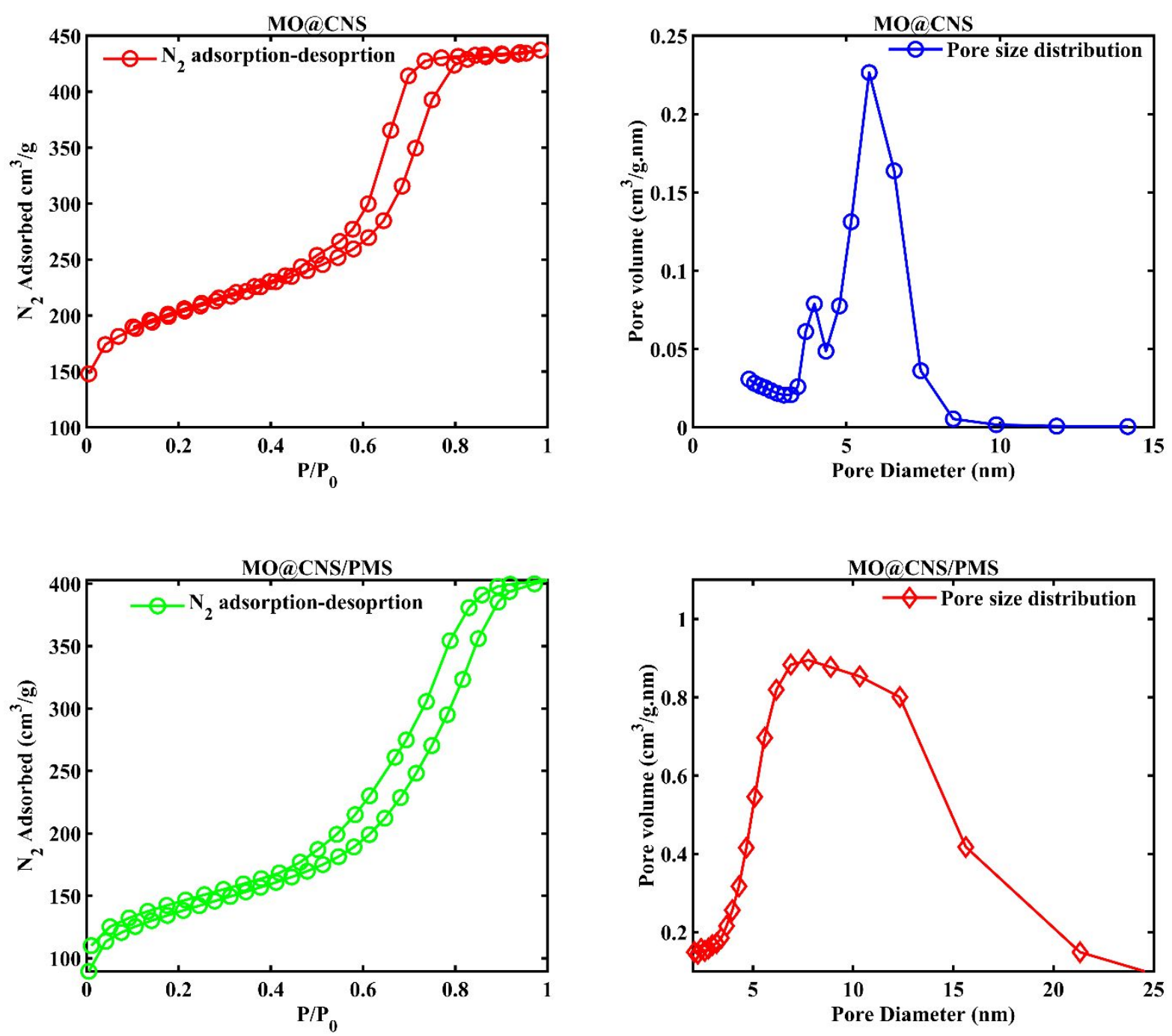

Figure S7. Nitrogen adsorption-desorption behaviour of regenerated MO@MCNS/PMS catalyst after phenol degradation
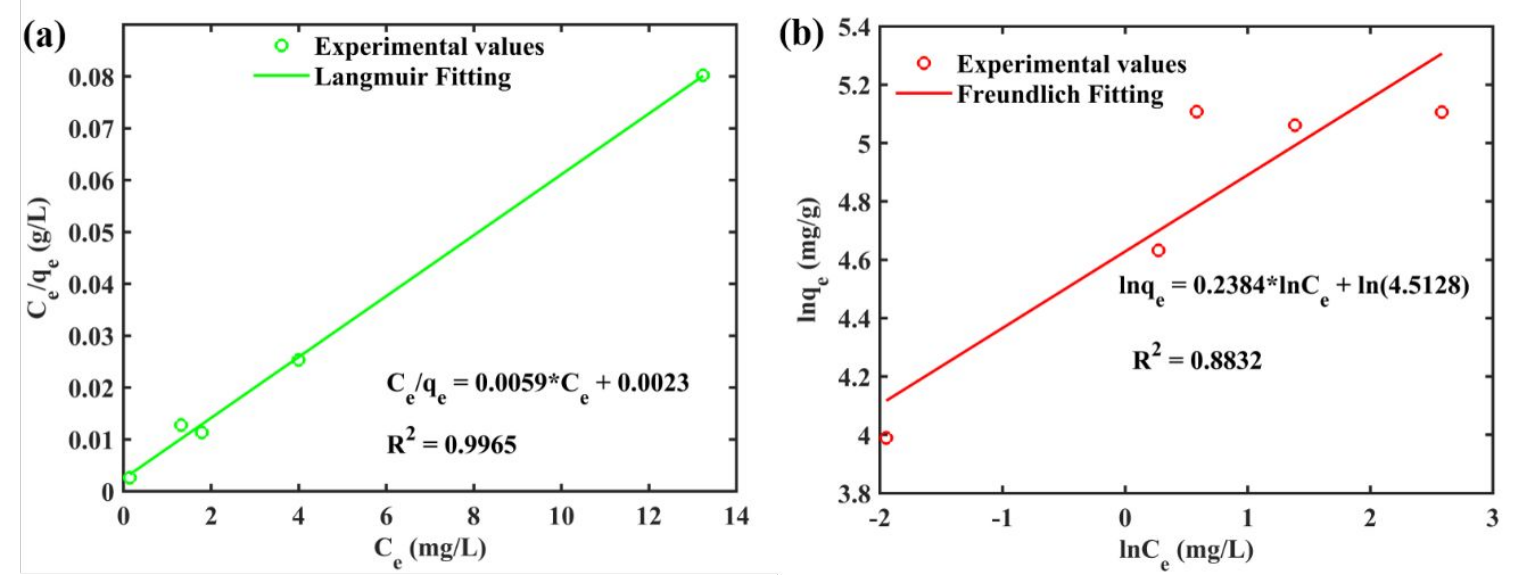

Figure S8 (a) Langmuir fitting and (b) Freundlich fitting parameters for experimental adsorption data of $\mathrm{p}$-HBA on PMS regenerated MCNS 

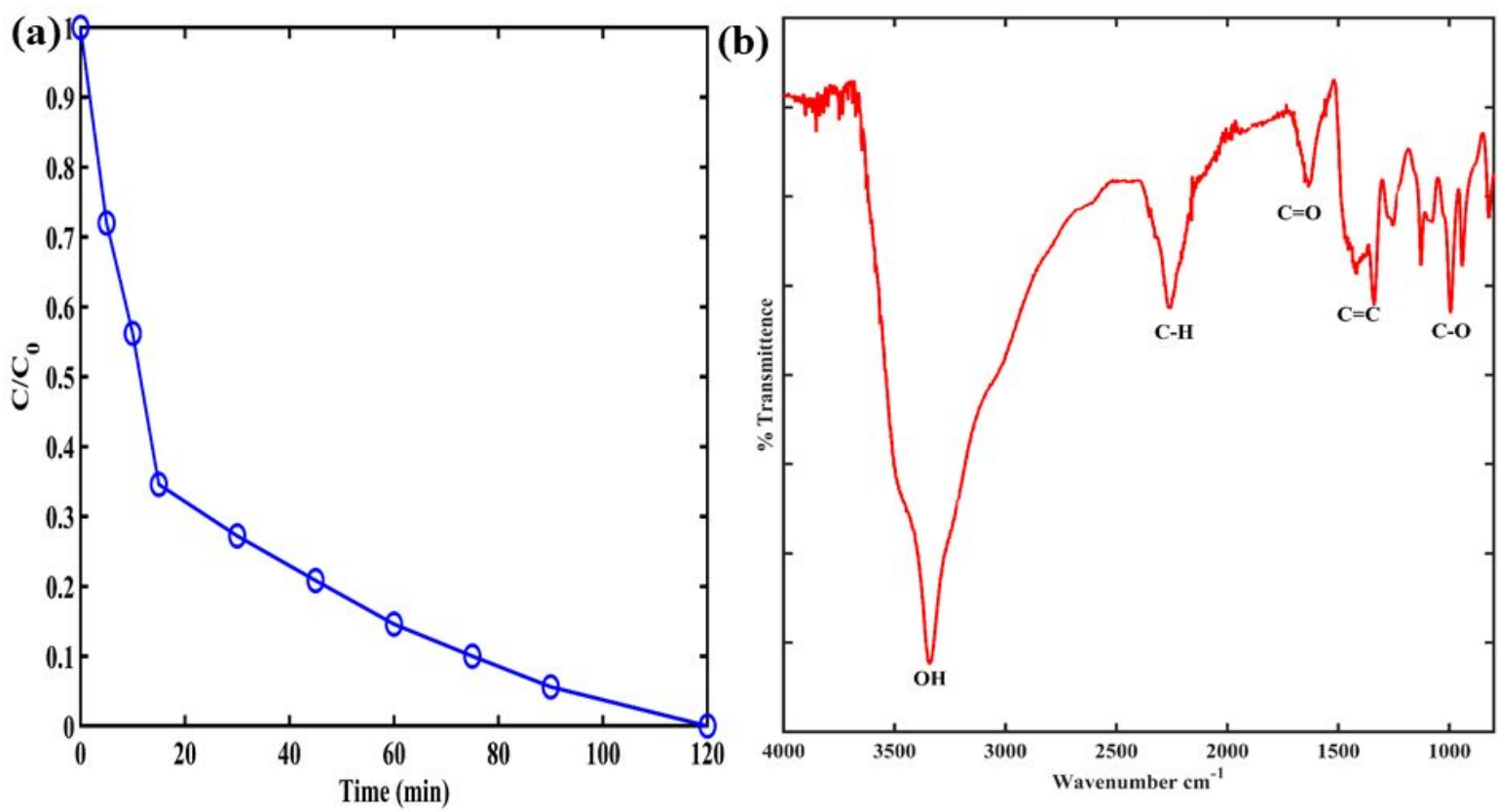

Figure S9. Catalytic degradation of phenol on secondary pre-adsorbed p-HBA@MCNS as catalyst $\mathrm{m}[\mathrm{cat}]=0.4 \mathrm{~g} \mathrm{~L}^{-1}, \mathrm{PMS}=1.62 \mathrm{mM}$ at $25^{\circ} \mathrm{C}$ (a) and FTIR spectra of used MCNS (b) 